Running head: TRUST AND PROSOCIAL BEHAVIOR

\title{
available at:
}

http: //jbd.sagepub.com/content/early/2015/05/11/0165025415584628.full

Children's Trust and the Development of Prosocial Behavior

Tina Malti ${ }^{1}$, Margit Averdijk ${ }^{2}$, Antonio Zuffianò ${ }^{1,3}$, Denis Ribeaud ${ }^{2}$,

Lucy R. Betts, ${ }^{4}$ Ken J. Rotenberg ${ }^{5}, \&$ Manuel P. Eisner ${ }^{6}$

${ }^{1}$ Department of Psychology, University of Toronto

${ }^{2}$ Chair of Sociology, Swiss Federal Institute of Technology Zurich (ETH)

${ }^{4}$ Fraser Mustard Institute for Human Development, University of Toronto

${ }^{5}$ Division of Psychology, Nottingham Trent University

${ }^{6}$ School of Psychology, Keele University

${ }^{6}$ Institute of Criminology, University of Cambridge

\section{Author Note}

Tina Malti, Department of Psychology, University of Toronto, Margit Averdijk and Denis Ribeaud, Chair of Sociology, Swiss Federal Institute of Technology, Antonio Zuffianò, Department of Psychology and Fraser Mustard Institute for Human Development, University of Toronto, Lucy R. Betts, Division of Psychology, Nottingham Trent University, Ken J. Rotenberg, School of Psychology, Keele University, Manuel P. Eisner, Institute of Criminology, University of Cambridge. The Zurich Project on the Social Development of Children and Youths was funded by, amongst others, the Swiss National Science Foundation, the Jacobs Foundation, the Swiss Federal Office of Public Health, and the Canton of Zurich Ministry of Education. The authors would like to express their sincere thanks to the children, parents, and teachers for participating in the study. Moreover, the authors are grateful to all the interviewers and undergraduate students for their help in data collection and coding and thank Anisha Aery and Nicole Raquinio, University of Toronto, for their editorial assistance with the manuscript.

Correspondence concerning this article should be addressed to Tina Malti, Department of Psychology, University of Toronto, 3359 Mississauga Road North, Mississauga, ON, L5L1C6, Canada. Electronic mail may be sent to tina.malti@utoronto.ca 


\begin{abstract}
This study examined the role of children's trust beliefs and trustworthiness in the development of prosocial behavior using data from four waves of a longitudinal study in a large, ethnically diverse sample of children in Switzerland (mean age $=8.11$ years at Time 1, $N=1,028)$. Prosocial behavior directed towards peers was measured at all assessment points by teacher reports. Children's trust beliefs and their trustworthiness with peers were assessed and calculated by a social relations analysis at the first assessment point using children's reports of the extent to which classmates kept promises. In addition, teacher reports of children's trustworthiness were assessed at all four assessment points. Latent growth curve modeling yielded a decrease in prosocial behavior over time. Peer- and teacher-reported trustworthiness predicted higher initial levels of prosocial behavior, and peer-reported trustworthiness predicted less steep decreases in prosocial behavior over time. Autoregressive cross-lagged analysis also revealed bidirectional longitudinal associations between teacherreported trustworthiness and prosocial behavior. We discuss the implications of the findings for research on the role of trust in the development of children's prosocial behavior.
\end{abstract}

Keywords: Trust, Prosocial Behavior, Peer Relations, Longitudinal Study 


\section{Children's Trust and the Development of Prosocial Behavior}

Trust is an essential aspect of human social interaction and an important basis for the development of fairness, care, and other-oriented concern (e.g., Putnam, 1993; Uslander, 2002). The notion that trust and trustworthiness promote other-oriented, prosocial behaviors, such as helping and co-operations, has been advanced from early on in social psychology (e.g., Deutsch, 1958). Similarly, developmental scientists have stressed the role of trust in children's psychosocial development and other-oriented concerns. For example, Erikson's psychosocial theory of human development (1963) emphasized that early trust development lays the ground for adaptive psychological development. Thus, a child's emerging feelings of trust in others and related moral skills, such as sensitivity to others' needs, may facilitate an orientation toward the needs of others and lead to morally relevant, prosocial behavior (van IJzendoorn, 1997; Rotenberg, 2010). Furthermore, social-cognitive researchers have emphasized from early on the role of trust and reciprocity in peer and friendship relations on other-oriented, prosocial behavior (Selman, 1980; see Gummerum \& Keller, 2008; Keller, 2004).

Here we systematically extend this line of work by studying whether children's trust in peer relations predict their prosocial behaviors toward peers from middle childhood to early adolescence. In addition, we also investigated reciprocal longitudinal associations between trust and prosocial behavior. To date, little developmental research has empirically examined the cross-sectional links between children's trust beliefs and prosocial behaviors (e.g., Chin, 2014). Reciprocal longitudinal evidence for this relationship is entirely absent. The present study aimed to fill this research gap and analyzed the role of children's trust beliefs and their own perceived trustworthiness in the development of prosocial behavior, as well as bidirectional longitudinal associations, in a large, ethnically diverse sample of children from 8 to 11 years of age, in Switzerland. 
Prosocial behavior has been defined as an action aimed to help or benefit others (Eisenberg \& Fabes, 1998; Eisenberg, Spinrad, \& Morris, 2014). Prosocial behaviors include various subdimensions, for example sharing, helping, co-operating, volunteering, and donating (Carlo, 2006). When measured together, these behaviors can be considered to comprise global or overt prosociality. Researchers have documented the numerous socialcognitive and social-emotional factors that affect the development of prosocial behavior (Eisenberg et al., 2014; Moore \& Macgillivray, 2004; Svetlova, Nichols, \& Brownell, 2010), including cross-sectional relations between prosocial behavior and trust (Rotenberg, 2010). Conceptually, the notion that co-operation and related other-oriented behaviors are promoted by trust has been emphasized since the past half century (Deutsch, 1958). Specifically, there are two distinct features of trust -- trust beliefs and trustworthiness -- that potentially impact prosocial behavior development. Trust beliefs are part of the social-cognitive and socialemotional domain of trust that comprises one's expectations that others fulfill promises, keep information confidential, and are honest (Rotenberg, 2010). Trustworthiness refers to an individual's tendency to engage in these types of behaviors (Rotenberg, 2010). Trust and trustworthiness have been regarded as essential to co-operation and, thus prosociality, for individuals often under the rubric of Social Capital, as a perceived social resource (Simpson, 2007). Theoretically, a relationship between trust and prosocial behavior is likely because trust comprises positive expectations about the behavior of others (Fehr, 2009). Individuals may share, help, or cooperate to fulfill these positive expectations and maintain a positive social reputation, as well as high self-esteem.

Research has yielded support for the hypothesis that engaging in other-oriented behavior - when there is risk of being exploited - is positively associated with individuals' trust beliefs in others and by others' trustworthiness (Simpson, 2007). For example, Ferrin, Bligh, and Kohles (2008) found that individuals' perceptions of the trustworthiness of their partner and partners' perceptions of their trustworthiness in a mixed motive game interaction 
predicted co-operation in a spiral fashion (i.e., perceived trustworthiness-spiral). There is evidence specifically that the belief that others fulfill promises and others fulfilling promises in a mixed-motive game predict development of co-operation (Rotenberg, 2004). Researchers have also found that trust beliefs are associated with prosocial behavior as directly evidenced by helping others and altruistic acts. For example, Rotenberg et al. (2005) found that children's trust in others was positively correlated with peer-reported helpfulness. Carlo, Randall, Rotenberg, and Armenta (2010) found that young adults' trust beliefs in close others were positively related to prosocial behaviors and altruism. Finally, Fehr (2009) found that adults who never engaged in volunteer activities held lower trust beliefs than those who volunteered in the social services.

Taken together, these studies provide empirical support for the assumption that trust is an important antecedent for other-oriented behaviors. However, the question that persists is whether both trust beliefs and trustworthiness longitudinally predict prosocial behavior during the course of middle childhood.

Researchers have found that children's trust beliefs and trustworthiness longitudinally predict trajectories of aggressive behavior across middle childhood (Malti, Averdijk, Rotenberg, Ribeaud, \& Eisner, 2013). However, aggression and prosocial behavior are conceptually distinct behaviors, and each contributes uniquely to subsequent development (e.g., Caprara, Dodge, Pastorelli, \& Zelli, 2006; Crick, 1996). It remains therefore to be determined whether children's trust beliefs and trustworthiness longitudinally predict other domains of social behavior, specifically prosocial behavior, in the same manner. The purpose of the current research was to address both questions.

\section{The Present Study}

In summary, the present study investigated relations between children's trust beliefs and trustworthiness to the development of prosocial behavior in four waves of a multiethnic longitudinal study. We deliberately chose to examine these research questions in middle 
childhood (i.e., 8 to 11 years of age) because it is at this time when relationships based on mutual trust emerge, and prior research has shown that children at this age prefer peer relationships that are characterized by trust (Kahn \& Turiel, 1988). Guided by previous research (Rotenberg et al., 2005), we assessed children's trust beliefs in peers and trustworthiness as ratings of promise-keeping elicited in peer reports. In addition, we assessed teacher reports of trustworthiness.

Based on the extant research on the development of teacher-reported prosocial behavior from middle childhood to early adolescence (Eisenberg et al., in press; Kokko et al., 2006; Nantel-Vivier et al., 2009), we expected to find a stability or slight decrease in prosocial behavior over time. We hypothesized that both children's trust beliefs in peers and trustworthiness would predict higher mean levels of prosocial behavior over time. Based on the theorizing that trust during middle childhood facilitates subsequent other-oriented behaviors, we expected that children who held more trust beliefs in peers and received high levels of trustworthiness as reported by their peers and teachers would be more likely to show less decrease in prosocial behavior than children who held lost trust beliefs and received low levels of trustworthiness. In addition, we also expected to see reciprocal relations between trust and prosocial behavior over time, as prosocial behavior may facilitate perceptions of trustworthiness. This, in turn, may motivate children to continue to engage in other-oriented behaviors, for example, to maintain their positive social reputation and/or positive self-worth created by being perceived as trustworthy by their peers and teachers. Earlier cross-sectional research has also provided some support for reciprocal relations between prosocial intentions and prosocial behaviors among friends in middle childhood. For example, Berndt and colleagues (1981a, 1981b) documented that fourth graders assumed that their friends would expect a moderate amount of prosocial behavior and would be more satisfied with their decisions about how much to share and help (Berndt, 1981a, 1981b). 
Because previous studies have indicated sex and socioeconomic status (SES) differences in prosocial behavior and trustworthiness (Benenson, Pascoe, \& Radmore, 2007; Betts \& Rotenberg, 2007; Eisenberg et al., in press; Malti, Gummerum, Keller, \& Buchmann, 2009), sex and SES were included as control variables.

\section{Method}

\section{Participants}

The data were drawn from the Zurich Project on the Social Development of Children and Youths, an ongoing combined longitudinal and intervention study. The sampling frame was formed by all 90 public primary schools in the city of Zurich from which a random sample of 56 schools, stratified by school size and school district, was drawn. The sample at the first assessment point consisted of 1,675 first graders from 56 elementary schools (for further details on the sampling procedure, see Eisner, Malti, \& Ribeaud, 2011). The present analysis focused on the longitudinal component of the study. We did not include the intervention condition as a control variable because we have shown elsewhere that there were no systematic effects on the outcome variable (i.e., prosocial behavior; Malti, Ribeaud, \& Eisner, 2011; for further details regarding the intervention component, see Eisner et al., 2011).

Forty-six percent of both parents were born outside of Switzerland (more than 80 countries of origin), which is fairly representative for the city of Zurich (Eisner et al., 2011). In terms of educational attainment of the parents, $24 \%$ had little or no secondary education, $32 \%$ had vocational training, $29 \%$ had attended vocational school, had earned a baccalaureate degree or advanced vocational diploma, and $16 \%$ had a university degree.

There were four data collection waves that took place annually between 2005 and 2009. In each wave, the data were collected from the child, the primary caregiver, and the teacher. In the present study, we analyzed data from the child, the teacher, and peers. The initial response rates were $81 \%$ for the child interviews $(N=1,361), 74 \%$ for the parent 
interviews $(N=1,240)$, and $81 \%$ for the teacher assessments $(N=1,350)$. For the present paper, we used the follow-up waves T1 through T4 (i.e., when children were in grade 2, 3, 4, and 5, respectively). In Switzerland, children enter elementary school at the age of 7. The retention rate at T1 was $97 \%$ for the child interviews and $96 \%$ for the teacher assessments (mean age $8.11, S D=.38$ ). For teacher assessments, the retention rate was $96 \%$ at $\mathrm{T} 2$ (mean age $9.21, S D=.37$ ), $92 \%$ at T3 (mean age $10.70, S D=.38$ ), and $77 \%$ at $\mathrm{T} 4$ (mean age 11.60 , $S D=.37)$. Parental consent had to be renewed at the fourth wave, thus resulting in a lower retention rate (see procedure section below). Nevertheless, the retention rate at $\mathrm{T} 4$ is still considered to be good for a large-scale longitudinal study (Cotter, Burke, Stouthamer-Loeber, \& Loeber, 2005).

Sample attrition effects were tested by comparing the children at T4 with those who did not participate at T4 $(N=275)$ on demographic variables (i.e., SES and sex $)$ and the study variables (i.e., trust beliefs, trustworthiness, and prosocial behavior). Children who did not participate at $\mathrm{T} 4$ were slightly more likely to have parents with low socio-economic status than children who stayed in the sample at T4, OR $=.98, p<.01$.

\section{Procedure}

Parents were asked to sign an informed consent form for T1-T3 at the beginning of the first wave and another informed consent form at the beginning of the fourth wave. Parental consent had to be renewed at the fourth wave because it was originally only obtained for three waves. Computer-assisted 45-min interviews with the children were conducted in Swiss German at schools by 44 interviewers who had been intensively trained by the research team. Teachers completed a questionnaire on the child's social behavior at all four assessment points.

\section{Measures}

Prosocial Behavior. At T1-T4, we used the Social Behavior Questionnaire (SBQ; Tremblay et al., 1991) to collect data on the child's prosocial behavior from the teachers. This 
instrument has been previously used in a variety of longitudinal studies, and it has been shown to be sensitive to behavior changes in intervention studies (e.g., Lacourse et al., 2002). We relied on teacher reports of children's social behavior for the present analysis because our trust measures were collected from children's classmates. Hence, teacher-ratings of social behavior are particularly well suited to test relations to trust as perceived among classmates, as both apply to the same situational context (i.e., the classroom). In addition, utilizing peer reports and teacher reports also helps overcome issues associated with common-method variance. The prosocial behavior scale included 7 items that were rated on a 5-point Likert scale ranging from 'never' to 'very often' (e.g., "shares things with peers”). All 7 items assessed prosocial behaviors directed toward peers. Cronbach's $\alpha$ was .92 at T1, .92 at T2, .91 at T3, and .92 at T4. The Zurich school system requires that children remain in the same class with the same teacher from Grade 1 to Grade 3, but they enter new classes in Grade 4 (i.e., middle school). Thus, the teachers at T1 and T2 were the same, and there were new teachers at $\mathrm{T} 3$ and $\mathrm{T} 4$, respectively.

Trust Beliefs and Trustworthiness. At T1, children's trust beliefs and their trustworthiness were assessed by their and their peers' perceptions that others/the self keeps promises. At T1-T4, trustworthiness was also assessed by teacher reports.

Peer nominations of trust beliefs and trustworthiness. Perceptions of promisekeeping served as primary measures of trust beliefs and trustworthiness in adults (Rotter, 1980) and in children (Betts \& Rotenberg, 2008; Hochreich, 1973) for over three decades. Researchers have assessed children's reports of promise-keeping per se because such behavior is observable by children in the natural social environment (Rotenberg et al., 2005). Furthermore, researchers have required children to judge the promise-keeping of several peers -- classmates -- because it yields multiple judgments, which are reliable and show validity (Rotenberg et al., 2004). As in previous research, participants were asked to rate each classmate on the extent to which they would keep a promise on a 5-point scale from never (1) 
to always (5). The participant was asked what 'keeping a promise' meant to him/her, and in the rare cases in which a child did not understand what it meant $(<1 \%)$, the interviewer explained that 'a promise is when someone says (s)he will do something, and keeping a promise is when this person indeed does what (s)he promised.' Participants were instructed to not share their answers with others after the interview. The measure is derived from a round robin design in which each participant rated, and was rated by, each of his/her classmates.

The measures of trust beliefs and trustworthiness were calculated by a social relation analysis (Kenny, Kashy, \& Cook, 2006) with the statistical software WinSoremo (Kenny \& Xuan, 2002). This program splits the trust ratings into components specific for the actor (i.e. a child's trust beliefs in classmates), the partner (i.e., the child's trustworthiness as rated by classmates), the relationship (one's behavior towards another individual, in particular, beyond the actor and partner components), and error variance. The relationship variance pertains to the unique ratings or behavior between individuals in dyadic relationships when the perceiver and target variance are statistically controlled for.

The Social Relation Analysis of the promise-keeping judgments yielded significant actor variance, $.17, p<.05$, which shows that there are reliable differences between participants in their beliefs that classmates keep promises. There was also a significant partner variance, $.15, p<.05$, which shows significant agreement among classmates in their reports of the promise-keeping of individual participants. The actor variance scores are used as the measure of trust beliefs and the partner variance scores are used as the measure of trustworthiness. The Social Relations Analysis ensured that trust beliefs and trustworthiness scores were statistically independent. The observed actor effects and partner effects as measures of trust beliefs and trustworthiness replicate those found in children from a range of cultures (e.g., Betts \& Rotenberg, 2008). Research has also yielded wide evidence for the reliability and validity of these measures (Rotenberg, Michalik, Eisenberg, \& Betts, 2008). On average, 9 children participated in the trust assessments per classroom $(M=9.02, S D=$ 
6.98; Range 0-25). In line with previous studies, the trust scores were only computed in classes with at least 5 participating children $(N=1,030)$ (Rotenberg, Betts, Eisner, \& Ribeaud, 2012).

Teacher reports of trustworthiness. At T1-T4, the honesty basis of trustworthiness was also assessed by teacher reports using two items ('s/he lies and cheats' and 's/he steals at school') of the SBQ's Non-Aggressive Conduct Disorder scale (Rotenberg et al., 2012; see Tremblay et al., 1991). This scale has been widely used in the literature (e.g., Stemmler, Loesel, Beelmann, Jaursch, \& Zenkert, 2005). The scale included 4 items that were rated on a 5-point Likert scale ranging from 'never' to 'very often' (e.g., 'tells lies and cheats'). The correlations between the two items were .45 at $\mathrm{T} 1, .46$ at $\mathrm{T} 2, .43$ at $\mathrm{T} 3$, and .42 at $\mathrm{T} 4$, all $p \mathrm{~s}<$ .001 . Greater scores reflected less lying/cheating and stealing and, thus, great trustworthiness (see Rotenberg et al., 2012).

Socioeconomic status. Socioeconomic status (SES) was based on coding the caregiver's current profession. The codes were then transformed into an International SocioEconomic Index of occupational status (ISEI) score (Ganzeboom, Degraaf, Treiman, \& Deleeuw, 1992). The final SES score was centered and based on the caregiver with the highest ISEI score.

\section{Treatment of Missing Data and Final Sample Size}

The peer-reported trust scores were only computed in classes with at least 5 participating children $(N=1,030)$ (Rotenberg et al., 2012). This was done to ensure that the estimates were based on a sufficient number of informants. Furthermore, data for two children were deleted because prosocial behavior scores were missing for all waves. This resulted in a final sample size of $N=1,028$. For the final analyses (i.e., latent growth curve models and autoregressive cross-lagged models), multiple imputation in Mplus 7.11 (Muthén \& Muthén, 2012) was used to account for missing data with 20 imputations in total. This approach allowed us the use exogenous variables with missing data such as SES (13\%) and 
teacher-reported trustworthiness $(0.7 \%)$ as predictors without losing further participants in the sample. We added indicators for parental education, ethnicity, financial problems, single parenthood, and full-time employment status (full-time versus part-time) to the imputation model to improve the predictive power of the SES indicator.

\section{Results}

\section{Descriptive Statistics}

The descriptive statistics and correlations between study variables are displayed in Table 1. As can be seen, prosocial behavior was significantly positively associated between assessment points. In addition, both peer-reported trustworthiness and teacher-reported trustworthiness were positively associated with prosocial behavior at all assessment points. Peer-reported trust beliefs at T1 were positively associated with peer-reported trustworthiness at $\mathrm{T} 1$, and they were positively related to teacher-reported trustworthiness at T2-T4.

\section{Predicting the Development of Prosocial Behavior from Trust Beliefs and}

\section{Trustworthiness}

To examine the effect of trust beliefs and trustworthiness at $\mathrm{T} 1$ on children's prosocial development from T1 to T4, we employed a Latent Growth Curve approach (LGC; Bollen \& Curran, 2006) with maximum-likelihood estimation of the parameters in Mplus 7.11 (Muthén \& Muthén, 2012). First, we identified the normative development of prosocial behavior from T1 to T4 (i.e., unconditional $L G M$ ) by estimating two growth latent factors that represented the initial status (i.e., the intercept) and change over time (i.e., the slope) of our targeted construct (i.e., prosocial behavior). To identify the best fitting unconditional model, we tested three nested models positing different growth trajectories and we compared each model using

the $\chi^{2}$ difference test (i.e., $\Delta \chi^{2}$ ). Next, once the best unconditional model had been identified, we ran a conditional LGM, including peer-reported trust beliefs and peer- and teacherreported trustworthiness at T1 as focal predictors, and gender and SES as control variables. Model fit was evaluated following standard recommendations (Kline, 2010): The $\chi^{2}$ 
likelihood ratio statistic, Comparative Fit Index (CFI), Root-Mean-Square-Error-ofApproximation (RMSEA) with associated 90\% CI, and the Root-Mean-Square-ResidualsStandardized (SRMR) were considered. A nonsignificant $\chi^{2}$-statistic is indicative of perfect fit (Kline, 2010). In terms of alternative fit indices, we accepted CFI $>.90$, RMSEA $<.08$, and SRMR <.06 (Kline, 2010).

Unconditional LGMs. We tested three different unconditional LGMs. In the strict stability model, we assumed a lack of growth in prosocial behavior by only estimating the latent intercept factor with factor loadings fixed at 1 at each time point. This model showed a very poor fit, $\chi^{2}(8)=212.93, p<.001, \mathrm{CFI}=.79, \mathrm{RMSEA}=.16(90 \%[\mathrm{CI}=.14, .18])$, $\mathrm{SRMR}=.19$. In the linear change model, we assumed a linear pattern of intra-individual change over time by adding a latent slope factor with factor loadings fixed at $0,1,2$, and 3 . In this model, the intercept represented children's level of prosocial behavior at T1. Although this LGM fit the data better than the previous model $\Delta \chi^{2}(3)=89.04, p<.001$, it still showed a poor fit $\chi^{2}(5)=123.89, p<.001, \mathrm{CFI}=.88, \mathrm{RMSEA}=.15(90 \%[\mathrm{CI}=.13, .18]), \mathrm{SRMR}=$ .07. In the non-linear change model, the shape of the change over time was not specified $a$ priori (for a more in depth discussion, see Bollen \& Curran, 2006). Specifically, we freely estimated the second and third factor loadings of the slope (i.e., T2, and T3) and we fixed at 0 and 1 for the first (T1) and the fourth (T4) factor loadings, respectively. By utilizing this approach, the parameters of the slope (i.e., mean and variance) captured the change of prosocial behavior from T1 to T4. This LGM fit the data reasonably $\chi^{2}(3)=15.58, p<.01$, $\mathrm{CFI}=.99, \mathrm{RMSEA}=.06(90 \%[\mathrm{CI}=.04, .10]), \mathrm{SRMR}=.04$, and improved the fit significantly of the previous model $\Delta \chi^{2}(2)=108.32, p<.001$. In this final model, both the mean $(M=2.34, p<.001)$ and the variance $\left(s^{2}=.33, p=.001\right)$ of the intercept were significant, suggesting that participants started with different initial levels of prosocial behavior. The mean of the slope revealed a slight decrease on average of prosocial behavior 
from $\mathrm{T} 1$ to $\mathrm{T} 4(M=-.11, p<.001)$, and the significance of the variance indicated interindividual differences in the overall decrease of prosocial behavior $\left(s^{2}=.09, p=.001\right){ }^{1}$

Conditional LGM. In the conditional LGM, we included gender $(0=\operatorname{girls} ; 1=$ boys $)$, SES, children's peer-reported trust beliefs, and peer- and teacher-reported trustworthiness at T1 as predictors of both intercept and slope. Additionally, we also regressed the slope on the intercept. This allowed us to estimate the effects of our focal predictors on the slope while partialling out the effect of initial differences in prosocial behavior on the rate of change over time. The conditional LGM fit the data well, $\chi^{2}(14)=36.57, p<.01, \mathrm{CFI}=.98, \mathrm{RMSEA}=$ $.04(90 \%[\mathrm{CI}=.02, .06]), \operatorname{SRMR}=.02 .{ }^{2} \operatorname{Gender}(\beta=-.37, p<.001)$ and $\operatorname{SES}(\beta=-.07, p<$ .05) predicted the intercept negatively (i.e., girls and children from a lower SES scored higher on prosocial behavior at T1). Children's trustworthiness, both according to peer-reports $(\beta=$ $.16, p<.001)$ and teacher-reports $(\beta=.19, p<.001)$, significantly predicted the intercept, indicating that higher values of trustworthiness were associated with a higher initial level of prosocial behavior. Importantly, peer-reported trustworthiness predicted the slope positively $(\beta=.22, p<.001)$, while controlling for the effects of gender $(\beta=-.39, p<.001)$ and intercept $(\beta=-1.08, p<.001)$. Specifically, higher values of trustworthiness at T1 predicted a lower decrease in prosocial behavior across time. Finally, the model accounted for a large part of the variance of both the intercept $\left(R^{2}=.24\right)$ and the slope $\left(R^{2}=.90\right)$ of prosocial behavior.

\section{Reciprocal, Longitudinal Associations between Prosocial Behavior and Trustworthiness}

An Autoregressive Cross-Lagged (ARC; Cole \& Maxwell, 2003) model with maximum-likelihood estimation of the parameters in Mplus 7.11 (Muthén \& Muthén, 2012) was implemented to analyze the direction of effects between prosocial behavior and teacherreported trustworthiness from T1-T4. Compared to standard cross-sectional analyses, ARC models are superior since they allow to control for the autoregressive prediction of the variables over time, thereby providing a more stringent and reliable estimate of the cross- 
lagged effects (Cole \& Maxwell, 2003). At each time point, prosocial behavior and trustworthiness were also regressed on sex and SES to partial out their effects from the crosslagged paths of interest. Possible developmental effects were assessed by imposing equality constraints on the strength of the unstandardized paths over time (Cole \& Maxwell, 2003). Specifically, we constrained (a) the autoregressive paths to be equal across time to test the temporal stability of the variables (e.g., prosocial behavior $\mathrm{T} 1 \rightarrow$ prosocial behavior $\mathrm{T} 2=$ prosocial behavior T2 $\rightarrow$ prosocial behavior T3), (b) the cross-lagged paths, to examine whether the strength of prediction varied over time (e.g., trustworthiness T1 $\rightarrow$ prosocial behavior T2 $=$ trustworthiness $\mathrm{T} 2$-> prosocial behavior T3), and (c) the residual covariances between prosocial behavior and trustworthiness within a time period (from T2 to T4). The plausibility of these equality constraints was examined with the $\Delta \chi^{2}$ test (i.e., constrained model vs. the unconstrained model). A non-significant $\Delta \chi^{2}$ test indicated the tenability of the constraints imposed. The same criteria for LGM were used to evaluate the model fit of ARC. The unconstrained ARC fit the data relatively well, $\chi^{2}(12)=58.41, p<.001, \mathrm{CFI}=$ $.98, \mathrm{RMSEA}=.06(90 \%[\mathrm{CI}=.05, .08]), \mathrm{SRMR}=.04 . \mathrm{Next}$, the constrained model in which only (a) the autoregressive path from trustworthiness at $\mathrm{T} 1$ to trustworthiness at $\mathrm{T} 2$, (b) the autoregressive path from prosocial behavior found in $\mathrm{T} 2$ to prosocial behavior found in $\mathrm{T} 3$ and (c) the covariance between prosocial behavior from T3 and trustworthiness from T3 were freely estimated fit the data well, $\chi^{2}(30)=86.30, p<.001, \mathrm{CFI}=.97, \mathrm{RMSEA}=.04(90 \%$ $[\mathrm{CI}=.03, .05]), \mathrm{SRMR}=.04 \mathrm{and}$, importantly, was not different from the unconstrained model, $\Delta \chi^{2}(18)=27.89, p=.06$ (see Figure 1). As reported in Figure 1, all autoregressive paths were significant, demonstrating a consistent degree of stability over time. Overall, the ARC model accounted for a moderate-large degree of variance of both prosocial behavior and trustworthiness. Importantly, prosocial behavior and trustworthiness exerted a small but significant $(p<.01)$ reciprocal influence at each time point, while controlling for the respective rank-order stability over time. 
To investigate the reciprocal flow of influence in more depth, we also tested whether the effects of each variable assessed at one time point (e.g., prosocial behavior at T1) on nonadjacent scores of the same variable (e.g., prosocial behavior at T3) were longitudinally mediated by the other variable in the model (i.e., trustworthiness at T2). The Monte Carlo (MC) confidence interval method with 20000 repetitions (Selig \& Preacher, 2008) was used to formally test the significance of the unstandardized mediated effect $(a b)$ because it has been found to offer good protection against Type-1 error (Hayes \& Scharkow, 2013). We found that (1) trustworthiness at T2 mediated the effect of prosocial behavior at T1 on prosocial behavior at T3 and (2) trustworthiness at T3 mediated the effect of prosocial behavior at T2 on prosocial behavior at T4 $(a b=.003,95 \%$ CI $[.001, .01])$. Similarly, (3) prosocial behavior at $\mathrm{T} 2$ mediated the effect of trustworthiness at $\mathrm{T} 1$ on trustworthiness at $\mathrm{T} 3$, and prosocial behavior at $\mathrm{T} 3$ mediated the effect of trustworthiness at $\mathrm{T} 2$ on trustworthiness at T4 $(a b=.003,95 \%$ CI $[.001, .01])$ (the mediated effects were the same since unstandardized cross-lagged parameters were constrained to equality over time). Finally, the effects of our control variable indicated that girls consistently scored higher than boys on both trustworthiness $(\beta \mathrm{s}$ from -.04 to $-.05, p \mathrm{~s}<.05)$ and prosocial behavior $(\beta \mathrm{s}$ from .14 to $-.26, p s<.01$ ); SES predicted higher trustworthiness at each time point $(\beta$ s from .10 to $.21, p \mathrm{~s}<.01)$ and slightly lower prosocial behavior at $\mathrm{T} 1(\beta=-.07, p<.05)$.

\section{Discussion}

The main aim of this study was to investigate the role of trust in peer relations on children's prosocial behavior directed toward peers. Researchers worldwide have argued that trust is essential to the existence of society and plays a crucial role in the attainment of competent social functioning and other-oriented behaviors (O'Hara, 2004; Uslander, 2002). In support of this view, research has shown that trust is positively linked to social functioning during childhood, adolescence (Bernath \& Feshbach, 1995), and adulthood (Simpson, 2007). 
In this research, we argued that children's trust beliefs and their trustworthiness in peer relations play an important role in morally relevant action tendencies toward peers, i.e., prosocial behaviors. Data from four waves of an ongoing longitudinal study in a large, ethnically diverse sample of children in Switzerland were utilized. We deliberately investigated these questions in middle childhood because this time period is characterized by qualitative transformations in children's peer relationship conceptions and the increasing importance of the concept of trust in children's peer relations and other-oriented behavior directed toward peers (Keller, 2004). Thus, this research is well suited to incorporate new knowledge on how trust relates to other-oriented behavior over time.

The first finding pertained to the role of trustworthiness in inter-individual differences in children's prosocial behavior. Specifically, the results indicated that both peer- and teacher-reported trustworthiness at the first assessment point predicted initial levels of prosocial behavior. Thus, children who were perceived as trustworthy by their peers and teachers when they were 8 years of age also showed higher levels of prosocial behavior compared to children who were perceived as less trustworthy. This finding shows that supportive peers and teachers who trust the child help children engage in high levels of otheroriented, prosocial behavior (Erikson, 1963; Noam \& Malti, 2010). Children might show high levels of prosocial behavior toward peers because their peers and teachers perceive them as trustworthy. Children may imagine that they need to be prosocial in the future to affirm the assumption made by their peers, which indeed may lead to an endorsement of other children's opinions on themselves as being prosocial and trustworthy.

The second finding pertained to the predictive role of trustworthiness in children's prosocial behavior development. Specifically, we found that children with high initial peerreported trustworthiness showed less steep decreases in prosocial behavior over time. This provides strong support for the theoretical notion that a feeling of being trusted by peers is crucial to pave the way for positive interpersonal relationships and facilitates children's 
other-oriented, prosocial behavior toward peers (Erikson, 1963; Selman, 1980). It is also in line with the notion of the norm of reciprocity in peer relationships (Staub, 1978), according to which children learn reciprocity in peer relationships, such as the norm if they help another child, the same child is more likely to help them in return. One of the motivations for helping in return might be that the child has become a trustworthy individual when helping, which is likely to be reciprocated with similar behavior in the future. Since our study focused on a sample of Swiss children and previous research has found cultural differences in trustworthiness, it might be interesting to explore if trustworthiness is even more predictive of other-oriented prosocial behaviors in cultures that value societal goals to share information with the peer group (Betts et al., 2014).

Interestingly, we did not find an impact of children's trust beliefs on their development of prosocial behavior. Possibly, trust in others may become more predictive of prosocial behavior in adolescence, when such beliefs become increasingly integrated in one's identity and self-concept (i.e., I am a person who trust others), and generalized trust beliefs in others (i.e., most people can be trusted), thereby motivating adolescents to behave according to their personal convictions. Additionally, perceptions by others might be more important for other-reported behaviors than self-reported trust in others. Future research is warranted to test if there are links between children's trust beliefs and self-reported or observed behaviors (Hay, 1994: Malti et al., in press). In line with previous findings, there was a slight developmental decrease in teacher-reported prosocial behavior over time (Nantel-Vivier et al., 2009). The decline in prosocial behavior may be due to children becoming more selective in their prosocial responses and increasingly differentiating towards whom they want to behave prosocially (Nantel-Vivier et al., 2009).

We also found evidence for bidirectional longitudinal associations between trustworthiness and prosocial behavior. Specifically, trustworthiness and prosocial behavior reciprocally affected each other over time, above and beyond the stability of both variables 
across time. Thus, children who were perceived as honest and reliable were more prosocial over time than their less trustworthy peers and, vice versa, prosocial children were perceived as increasingly trustworthy across middle- to late childhood. Behaving prosocially may increase children's trustworthiness because helping, caring, and sharing are behaviors highly valued by significant others (e.g., peers, teachers, parents, etc.), that in the long run, can contribute to create a positive image of the child as honest, ethical, and responsible. On the other hand, it is likely that being perceived as trustworthy can motivate children to behave prosocially in order to be consistent with others' positive expectations, thereby helping them to maintain a positive image of themselves. In line with this reasoning, our mediational analysis revealed that the effect of prosocial behavior at $\mathrm{T} 1$ on prosocial behavior at $\mathrm{T} 3 \mathrm{was}$ mediated by the effect of trustworthiness at T2 and vice-versa. Therefore, reinforcing mechanisms (e.g., higher prosocial behavior leads to higher trustworthiness that, in turn, leads to higher prosocial behavior) seem to be operating in the reciprocal relations linking prosocial behavior and trustworthiness. This is important for the design of educational programs that aim at promoting children's and adolescents' prosocial behavior, as the enhancement of positive peer relationships and an associated increase in trustworthiness may contribute to subsequent increases in prosocial behaviors.

Consistent with previous research, our findings indicated that girls were more likely to be rated as prosocial compared to boys (Eisenberg et al., in press). As expected, girls were also perceived as more trustworthy by their peers and, in part, by their teachers, than boys (Betts \& Rotenberg, 2007). This finding is likely related to the socialization of gender roles in boys and girls. For example, girls are frequently socialized to be nice, which is likely to increase one's trustworthiness (Malti, Gummerum, Keller, Chaparro, \& Buchmann, 2012).

Furthermore, children from families with higher socioeconomic status were rated as more trustworthy by their teachers compared to children from families with lower socioeconomic status. Research indicates that children from families with lower 
socioeconomic status do show less social and emotional well-being than children from families with higher socioeconomic status (Bradley \& Corwin, 2002), which is related to limited access to material and social resources, and increased stigma and negative stereotypes. Prosocial behavior was negatively associated with SES, although the effect was small. Because findings on the effect of SES on children's and adults' prosocial behavior remain fairly inconsistent (e.g., Benenson et al., 2007; Piff, Kraus, Cote, Cheng, \& Keltner, 2010), future research is warranted.

The present study had several limitations: Although we relied on longitudinal data and the findings demonstrated the hypothesized links between children's trust and the development of prosocial behavior, some researchers have argued that multiple informants should be used to measure prosocial behavior. However, teacher ratings have been shown to be very reliable and valid indicators of prosocial behavior (Malti \& Krettenauer, 2013), and we used data from multiple informants (i.e., teachers and peers) to overcome commonmethod biases. Additionally, the presence of different teachers at T3 and T4 might have introduced some additional sources of undesirable variability in evaluating children's trustworthiness and prosocial behavior. However, the rank-order stability of the variables was relatively high at each time-lag, thus reducing this potential source of bias. We are also aware that our cross-lagged coefficients were small in terms of effect sizes. Yet, these effects must be properly weighted against the highly stringent longitudinal ARC analysis adopted. Indeed, they are in accordance with the ones found in previous studies adopting similar stringent longitudinal ARC models (Adachi \& Willoughby, 2014). In addition, even small cross-lagged coefficients can be meaningful in ARC models since they represent consistent additive effects that can have important long-term effects on children's development (Adachi \& Willoughby, 2014). Lastly, due to the large-scale nature of our study, the assessment of prosocial behavior was limited to overt prosocial behavior. Conceptually, links between trust and cooperative behavior are particularly reasonable, and future research is necessary to investigate 
differential links between trust and the development of various subtypes of prosocial behavior, such as cooperation, helping, and sharing.

In summary, the present research provided new insights into how children's trust is linked with the development of prosocial behavior. This understanding is of interest not only for theoretical reasons, but also because of its relevance to educational interventions that aim to promote prosocial behavior and social inclusion by strengthening interpersonal trust. 


\section{References}

Adachi, P., \& Willoughby, T. (2014). Interpreting effect sizes when controlling for stability effects in longitudinal autoregressive models: Implications for psychological science. European Journal of Developmental Psychology, 12, 116-128. doi: $10.1080 / 17405629.2014 .963549$

Benenson J.F., Pascoe, J., \& Radmore, N. (2007). Children's altruistic behavior in the dictator game. Evolution and Human Behavior, 28, 168-175. doi: 10.1016/j.evolhumbehav.2006.10.003

Berlin, K.S., Parra, G.R., \& Williams, N.A. (2013). An introduction to latent variable mixture modeling (part 2): Longitudinal latent class growth analysis and growth mixture models. Journal of Pediatric Psychology, 39, 188-203. doi: 10.1093/jpepsy/jst085

Bernath, M.S., \& Feshbach, N. (1995). Children's trust: Theory, assessment, development, and research directions. Applied \& Preventive Psychology, 4, 1-19. doi: 10.1016/S0962-1849(05)80048-4

Berndt, T.J. (1981a). Age changes and changes over time in prosocial intentions and behavior between friends. Developmental Psychology, 17, 408-416. doi: 10.1037/00121649.17.4.408

Berndt, T.J. (1981b). The effects of friendship on prosocial intentions and behavior. Child Development, 52, 636-643. doi: 10.2307/1129184

Betts, L.R., \& Rotenberg, K.J. (2007). Trustworthiness, friendships and self-control: Factors that contribute to young children's school adjustment. Infant and Child Development, 16(5), 491-508. doi: 10.1002/icd.518

Betts, L. R., \& Rotenberg, K. J. (2008). A social relations analysis of young children's trust in their peers across the early years of school. Social Development, 17, 1039-1055. doi: 10.1111/j.1467-9507.2008.00479.x

Betts, L.R., Rotenberg, K.J., Ptrocchi, S., Leccisco, F., Sakai, A., Maeshiro, K., \& Judson, H. 
(2014). An investigation of children's peer trust across culture: Is the composition of peer trust universal? International Journal of Behavioral Development, 38, 33-41. doi: $10.1177 / 0165025413505248$

Bollen, K.A., \& Curran, P.J. (2006). Latent curve models: A structural equation approach. Hoboken: Wiley. doi: 10.1007/s11336-007-9011-6

Bradley, R.H., \& Corwyn, R.F. (2002). Socioeconomic status and child development. Annual Review of Psychology, 53, 371-399. doi: 10.1146/annurev.psych.53.100901.135233

Buse, A. (1982). The likelihood ratio, Wald, and Lagrange multiplier tests: An expository note. The American Statistician, 36(3), 153-157. doi: 10.2307/2683166

Caprara, G.V., Dodge, K.A., Pastorelli, C., \& Zelli, A. (2006). Conduct Problems Prevention Research Group. The effects of marginal deviations on behavioral development. European Psychologist, 11(2), 79-89. doi: 10.1027/1016-9040.11.2.79

Carlo, G. (2006). Care-based and altruistically-based morality. In M. Killen \& J. G. Smetana (Eds.), Handbook of moral development (pp. 551-579). Mahwah, NJ: Lawrence Erlbaum.

Carlo, G., Randall, B.A., Rotenberg, K.J., \& Armenta, B.E. (2010). Exploring the relations among trust beliefs, prosocial tendencies, and friendships. In K.J. Rotenberg (Ed.), Interpersonal trust during childhood and adolescence (pp. 270-294). New York: Cambridge University Press. doi: 10.1017/CBO9780511750946.013

Chin, J. (2014). Young children's trust beliefs in peers: Relations to social competence and interactive behavior in a peer group. Early Education and Development, 25, 601-618. doi:10.1080/10409289.2013.836698

Cole, D.A., \& Maxwell, S.E. (2003). Testing mediational models with longitudinal data: questions and tips in the use of structural equation modeling. Journal of Abnormal Psychology, 112, 558-577. doi:10.1037/0021-843X.112.4.558 
Cotter, R.B., Burke, J.D., Stouthamer-Loeber, M., \& Loeber, R. (2005). Contacting participants for follow-up: how much effort is required to retain participants in longitudinal studies? Evaluation and Program Planning, 28, 15-21. doi: 10.1016/j.evalprogplan.2004.10.002

Crick, N. R. (1996). The role of overt aggression, relational aggression, and prosocial behavior in the prediction of childre s future social adjustment. Child Development, 67, 2317-2327. doi: 10.2307/1131625

Deutsch, M. (1958). Trust and suspicion. Journal of Conflict Resolution, 2, 265-279. doi: $10.1177 / 002200275800200401$

Eisenberg, N., \& Fabes, R. A. (1998). Prosocial development. In W. Damon \& N. Eisenberg (Eds.), Handbook of child psychology (5 ${ }^{\text {th }}$ ed), Vol. 3: Social, emotion and personality development (pp.701-708). Hoboken: Wiley.

Eisenberg, N., Spinrad, T. L., \& Knafo, A. (in press). Prosocial development. In M. E. Lamb (Ed.), Handbook of child psychology and developmental science, Vol. 3: Social and emotional development. New York, NY: Wiley.

Eisenberg, N., Spinrad, T. L., \& Morris, A. S. (2014). Empathy-related responding in children. In M. Killen \& J. Smetana (Eds.), Handbook of moral development (2nd edition) (pp. 163-183). New York: Psychology Press.

Eisner, M.P., Malti, T., \& Ribeaud, D. (2011). Large-scale criminological field experiments. In S. Gadd, S. Karstedt, \& S. Messner (Eds.), Sage handbook of criminological research methods (pp. 410-424). London: Sage.

Erikson, E. H. (1963). Childhood and society (2nd ed.). New York: Norton.

Fehr, E. (2009). On the economics and biology of trust. Journal of the European Economic Association, 7 (2-3), 235-266. doi: 10.1162/JEEA.2009.7.2-3.235

Ferrin, D. L., Bligh, M. C., \& Kohles, J. C. (2008). It takes two to tango: An interdependence analysis of the spiraling of perceived trustworthiness and cooperation in interpersonal 
and intergroup relationships. Organizational Behavior and Human Decision Processes, 107, 161-178.

Ganzeboom, H. B. G., Degraaf, P. M., Treiman, D. J., \& Deleeuw, J. (1992). A standard international socio-economic index of occupational status. Social Science Research, 21, 1-56. doi: dx.doi.org/10.1016/0049-089X(92)90017-B

Gummerum, M., \& Keller, M. (2008). Affection, virtue, pleasure, and profit: Developing an understanding of friendship closeness and intimacy in Western and Asian cultures. International Journal of Behavioral Development, 32, 130-143. doi: $10.1177 / 0165025408089271$

Hay, D.F. (1994). Prosocial development. Journal of Child Psychology and Psychiatry, 35, 29-71. doi: 10.1111/j.1469-7610.1994.tb01132.x

Hayes, A. F., \& Scharkow, M. (2013). The relative trustworthiness of inferential tests of the indirect effect in statistical mediation analysis: Does method really matter? Psychological Science, 24, 1918-1927. doi: 10.1177/0956797613480187

Hochreich, D. J. (1973). A children's scale to measure interpersonal trust. Developmental Psychology, 9, 141. doi: 10.1037/h0035085

Kahn, E.H., \& Turiel, E. (1988). Children's conceptions of trust in the context of social expectations. Merrill-Palmer Quarterly, 34, 403-419.

Keller, M. (2004). Self in relationship. In D. K. Lapsley \& D. Narvaez (Eds.), Moral development, self, and identity (pp. 267-298). Mahwah, NJ: Erlbaum.

Kenny, D. A., Kashy, D. A., \& Cook, W. L. (2006). Dyadic data analysis. New York: Guilford Press.

Kenny, D. A., \& Xuan, A. (2002). Winsoremo [computer software].

Kline, R.B. (2010). Principles and practices of structural equation modeling ( $3^{\text {rd }}$ ed.). New York: Guilford. 
Kokko, K., Tremblay, R.E., Lacourse, E., Nagin, D.S., \& Vitaro, F. (2006). Trajectories of prosocial behavior and physical aggression in middle childhood: Links to adolescents school dropout and physical violence. Journal of Research on Adolescence, 16(3), 403428. doi: 10.1111/j.1532-7795.2006.00500.x

Lacourse, E., Côté, S., Nagin, D. S., Vitaro, F., Brendgen, M., \& Tremblay, R. E. (2002). A longitudinal-experimental approach to testing theories of antisocial behavior development. Development and Psychopathology, 14, 909-924. doi: $10.1017 / \mathrm{S} 0954579402004121$

Malti, T., Averdijk, M., Ribeaud, D., Rotenberg, K., \& Eisner, M.P. (2013). “Do you trust him?" Children's trust beliefs and developmental trajectories of aggressive behavior in an ethnically diverse sample. Journal of Abnormal Child Psychology, 41(3), 445-456. doi: $10.1007 / \mathrm{s} 10802-012-9687-7$

Malti, T., Gummerum, M., Keller, M., \& Buchmann, M. (2009). Children's moral motivation, sympathy, and prosocial behavior. Child Development, 80, 442-460. doi: 10.1111/j.1467-8624.2009.01271.x

Malti, T., Gummerum, M., Keller, M., Chaparro, M.P., \& Buchmann, M. (2012). Early sympathy and social acceptance predict the development of sharing in children. PLoS ONE, 7(12), e52017. doi: 10.1371/journal.pone.0052017

Malti, T., Gummerum, M., Ongley, S. F., Chaparro, M. P., Nola, M., \& Bae, N.Y. (in press). Who is worthy of my generosity? Recipient characteristics and children's sharing behavior. International Journal of Behavioral Development.

Malti, T., \& Krettenauer, T. (2013). The relation of moral emotion attributions to prosocial and antisocial behavior: A meta-analysis. Child Development, 84(2), 397-412. doi: 10.1111/j.1467-8624.2012.01851.x 
Moore, C., \& Macgillivray, S. (2004). Social understanding and the development of prudence and prosocial behavior. In J. Baird \& B. Sokol (Eds.), New Directions for Child and Adolescent Development (pp. 51-62). San Francisco: Jossey-Bass.

Muthén, L., \& Muthén, B. (2012). Mplus user's guide. Los Angeles, CA: Muthén \& Muthén. Nantel-Vivier, A., Kokko, K., Caprara, G.V., Pastorelli, C., Gerbino, M.G., Paciello, M., .. . Tremblay, R.E. (2009). Prosocial development from childhood to adolescence: A multiinformant perspective with Canadian and Italian longitudinal studies. Journal of Child Psychology and Psychiatry, 50(5), 590-598. doi: 10.1111/j.1469-7610.2008.02039.x

Noam, G.G., \& Malti, T. (2010). Ego development. In I. B. Weiner \& E. Craighead (Eds.), The Corsini encyclopedia of psychology, Volume 2 (pp. 549-552). New York: Wiley. doi: 10.1002/9780470479216.corpsy0296

O’Hara, K. (2004). Trust: From Socrates to Spin. Cambridge: Cambridge University Press. Piff, P.K., Kraus, M.W., Cote, S., Cheng, B.H., \& Keltner, D. (2010). Having less, giving more: The influence of social class on prosocial behavior. Journal of Personality and Social Psychology, 99(5), 771-784. doi: 10.1037/a0020092

Putnam, R.D. (1993). Making democracy work. Civic traditions in modern Italy. Princeton: Princeton University Press.

Rotenberg, K. J. (2010). Introduction. In Ken J. Rotenberg (Ed). Interpersonal trust during childhood and adolescence (pp. 3-7). New York: Cambridge University Press. doi: 10.1017/CBO9780511750946.001

Rotenberg, K. J., Betts, L. R., Eisner, M., \& Ribeaud, D. (2012). Social antecedents of children's trustworthiness. Infant and Child Development, 21(3), 310-322. doi: 10.1002/icd.751

Rotenberg, K. J., Fox, C., Green, S., Ruderman, L., Slater, K., Stevens, K., et al. (2005). Construction and validation of children's interpersonal trust belief scale. British Journal Developmental Psychology, 23, 271-292. doi: 10.1348/026151005X26192 
Rotenberg, K. J., McDougall, P., Boulton, M. J., Vallancourt, T., Fox, C., \& Hymel, S. (2004). Cross sectional relations among trustworthiness, social relationships, and psychological adjustment in children and early adolescents from the United Kingdom and Canada. Journal of Experimental Child Psychology, 88, 46-67. doi: 10.1016/j.jecp.2004.01.005

Rotenberg, K.J., Michalik, N., Eisenberg, N., \& Betts, L. (2008). The relations among young children's peer-reported trustworthiness, inhibitory control, and preschool adjustment. Early Childhood Research Quarterly, 32(2), 288-298. doi: 10.1016/j.ecresq.2007.04.003

Rotter, J. B. (1980). Interpersonal trust, trustworthiness and gullibility. American Psychologist, 35, 1-7. doi: 10.1037/0003-066X.35.1.1

Selig, J. P., \& Preacher, K. J. (2008, June). Monte Carlo method for assessing mediation: An interactive tool for creating confidence intervals for indirect effects [Computer software]. Available from http://quantpsy.org/.

Selman, R. L. (1980). The growth of interpersonal understanding. New York: Academic Press.

Simpson, J. A. (2007). Foundations of interpersonal trust. In A.W. Kruglanski \& E.T. Higgins (Eds.), Social psychology: Handbook of basic principles (2nd ed., pp. 587607). New York: Guilford Press.

Staub, E. (1978). Positive social behavior and morality: Vol. 1. Social and personal influences. New York: Academic.

Stemmler, M., Lösel, F., Beelmann, A., Jaursch, S., \& Zenkert, B. (2005). Child problem behavior in kindergarten and in primary school: A comparison between prediction configural frequency analysis and multiple regression. Psychology Science, 47, 467478.

Svetlova, M., Nichols, S., \& Brownell, C. (2010). Toddlers' prosocial behavior: From 
instrumental to empathic to altruistic helping. Child Development, 81, 1814-1827. doi: 10.1111/j.1467-8624.2010.01512.x

Tremblay, R. E., Loeber, R., Gagnon, C., Charlebois, P., Larivee, S., \& LeBlanc, M. (1991). Disruptive boys with stable and unstable high fighting behavior patterns during junior elementary school. Journal of Abnormal Child Psychology, 19, 285-300. doi:

10.1007/BF00911232

Uslander, E. M. (2002). The moral foundations of trust. Cambridge: Cambridge University Press.

van IJzendoorn, M.H. (1997). Attachment, emergent morality, and aggression: Toward a developmental socioemotional model of antisocial behaviour. International Journal of Behavioral Development, 21(4), 703-727. doi: 10.1080/016502597384631

Wentzel, K. R. (1991). Relations between social competence and academic achievement in early adolescence. Child Development, 62, 1066-1078. doi: 10.2307/1131152 
Notes.

${ }^{1}$ Modification indices suggested the need to estimate the covariance between the residual variances of prosocial behavior at T3 and T4 in each model. We captured the covariance between these two residual variances by estimating a further latent factor that was uncorrelated with the latent growth factors (i.e., intercept and slope). To allow model identification, residual variances of prosocial behavior at $\mathrm{T} 1, \mathrm{~T} 3$ and $\mathrm{T} 4$ were constrained to equality.

${ }^{2}$ Since the slope showed a small and non-significant negative residual variance, we fixed this latter at a very small value (i.e., .01) to allow model identification (Berlin, Parra, \& Williams, 2013). 
Table 1

Descriptive Statistics for Study Variables

$\begin{array}{llllllllllll}1 & 2 & 3 & 4 & 5 & 6 & 7 & 8 & 9 & 10 & 11 & 12\end{array}$

1. Prosocial behavior Time 1

2. Prosocial behavior Time $2 \quad .67 * * \quad-$

3. Prosocial behavior Time $3 \quad .31 * * \quad .36 * * \quad-$

4. Prosocial behavior Time $4 \quad .25^{* *} \quad .30^{* *} \quad .57^{* *} \quad-$

$\begin{array}{lllllll}\text { 5. Trust beliefs (Peer-report) } & .06 & .05 & .06 & .04 & -\end{array}$

Time 1

6. Trustworthiness (Peer-report) $\quad .20^{* *} \quad .19^{* *} \quad .21^{* *} \quad .20^{* *} \quad .37^{* *} \quad-$

Time 1

7. Trustworthiness (Teacher-

$\begin{array}{llllll}.18 * * & .18 * * & .12 * * & .14 * * & .05 & .29 * *\end{array}$

report) Time 1

8. Trustworthiness (Teacher- $\quad .18^{* *} \quad \begin{array}{llllllll} & .27 * & .13^{* *} & .16^{* *} & .08^{*} & .31 * * & .54 * * & -\end{array}$

report) Time 2

9. Trustworthiness (Teacher-

$\begin{array}{llllllll}.13 * * & .14 * * & .29 * * & .21 * * & .10^{* *} & .29 * * & .32 * * & .33 * *\end{array}$

report) Time 3

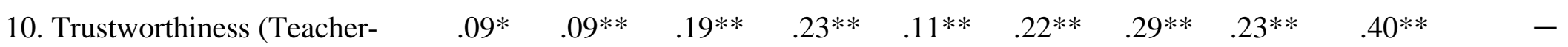

report) Time 4 
Note. $N=1,028$. Sex $(0=$ Girls, $1=$ Boys $)$. Prosocial behavior $(1=$ never to $5=$ very often $)$, trust beliefs $(1=$ never to $5=$ always $)$, and trustworthiness $(1=$ never to $5=$ very often) were rated on a 5 -point Likert scale ranging from 1 to 5 (higher scores indicate more of that quality). $* p<.05 . * * p<.01$. 


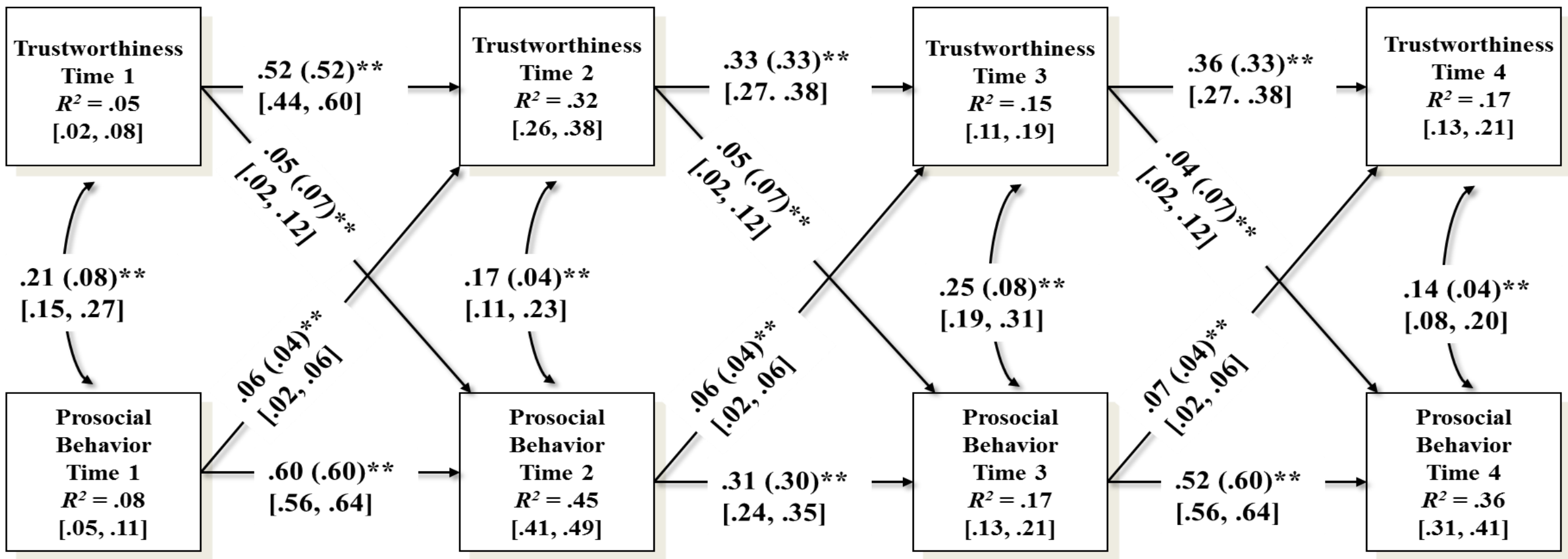

Figure 1. Autoregressive Cross-Lagged Model.

Note. $N=1,028$. Prosocial behaviors and trustworthiness were rated on a 5-point Likert scale ranging from 1 (never) to 5 (very often). Higher scores indicate more of that quality. Standardized and unstandardized (in parentheses) parameters were reported. Confidence intervals (95\%) for unstandardized betas, correlations, and R-squared values $\left(R^{2}\right)$ were reported in brackets.The effects of sex and socioeconomic status were estimated but not depicted for simplicity. ${ }^{*} p<.05 ; * * p<.01$. 